\title{
Comparative Study on Talk Shows in China and America from Hosting Styles
}

\author{
Hongli $\mathrm{Wu}^{1}$, Jingjing $\mathrm{Lu}^{1}$ \\ ${ }^{I}$ Zhejiang Ocean University, Zhoushan, China \\ *Corresponding Author: Hongli Wu, Zhejiang Ocean University No.1,Haida South Road, Lincheng \\ Changzhi Island, Zhoushan, Zhejiang, 316022 P.R. China
}

\begin{abstract}
With the popularization of talk show these years, we find that there are different features of its development between China and America, such as the differences on hosting styles, on the values, on the program patterns and on its profound influence. The paper starts with the definition and origination about talk show. After introducing it generally, the author presents some representative programs in China and America, such as Tonight's Post-80s Talk Show, Bao Zou Big News Event, Oprah Winfrey Show, Late Show with David Letterman and so on, and analyzes the different hosting styles that put the talk show on a distinctive trend in development. As world becomes a smaller and smaller village, it is essential for talk show in China to get further development by learning the advantages from America.
\end{abstract}

Keywords: talk show; differences; hosting styles; further development

\section{INTRODUCTION}

\subsection{Definition and Origination}

Talk show refers to a talk program. The common pattern is the talk between a host and one or more guests. As a face-to-face discourse type, talk show is a relatively recent and insufficiently explored area of pragmalinguistic studies, although conversation analysis and discourse analysis have been applied to the examination of question-answer adjacency pairs in several face-to-face discourse types, such as casual conversation, courtroom interaction, classroom interaction, doctor-patient dialogue and news interviews. (Ilie,1999) Talk show originates from England in 18 Century, people used to talk about entertainment politics in the coffee shop, where the early talk show was born. Because of the production of radio and television technology, the real talk show developed in the United States. At that time, China regarded such programs as "talk show", and the "entertainment talk show" now mentioned owns the features of China's localization.(Guo, 2016) Like the soap opera, the television talk show is an invention of twentieth century broadcasting. It takes a very old form of communication, conversation, and transforms it into a low cost but highly popular form of information and entertainment through the institutions, practices and technologies of television.(Zhou $\& \mathrm{Wu}, 2008)$

\subsection{Classification}

There are three classifications of talk show. First, from the perspective of medium pattern, it can be divided into broadcast talk show and television talk show. Second, from the perspective of program pattern, talk show is not fixed and changeless. Most of the programs are free and relaxing talks between the host and guests, like Oprah Winfrey Show. Some other programs, like Bao Zou Big News Event, is a one-man talk show. The host Wang Nima stands on a small stage, introducing some heated topics from a humorous perspective. Third, from the perspective of program content, talk show can be divided into News Talk, Entertaining Talk, Major Social Events Talk, and Sales Talk.

\subsection{Writing Purpose}

With the popularization of talk show these years, more and more different kinds of talk shows have appeared in China. However, we find that there are different features of its development between 
China and America, such as the differences on hosting styles, on the values, on the program patterns and on its profound influence. As world becomes a smaller and smaller village, it is essential for talk show in China to get further development by learning the advantages from America. And the host must hold great responsibility for it.

\section{The Hosting Style In Chinese Talk Show}

\subsection{Tonight's Post-80s Talk Show}

On May, 13, 2012, Oriental TV launched a new talk show, named Tonight's post-80s talk show. The show aroused a huge sensation and got high ratings. The reasons of these great achievements cannot be separated with the host's humorous style. Tonight's post-80s talk show still follows the previous sarcastic style, but it becomes more fashionable and international. The central figure of a program must be the host and the role the host plays in the program is to use the context. On the one hand, the host spreads the content expressed by the creative team to the audience. On the other hand, he also needs feedback from the audience to fill in and explain the content and conduct two-way exchanges. So the host plays an important role in the program. And as to the host, his words and deeds must be consistent with the style of the show. At this point, tonight's post-80s talk show is also true, the host Wang Zijian is the origin of learning comic dialogue, so he is good at "saying" "learning" "amusing" and "singing", and his style is very humorous. Wang Zijian's implementation of the chairmanship is not only to amuse the audience, but also to express some truth through some narratives by ridiculing some of the social issues in a humorous way and expressing the inner voices of most people.(Yang, 2017:199)

\subsection{Bao Zou Big News Event}

Currently, the one-man talk show named Bao Zou Big News Event gains plenty of favorable impression and support from audiences. In Chinese, "bao zou" means something pushes somebody over the edge, so we can easily get the position of Bao Zou Big News Event---a talk show talking about satirical news. The host Wang Nima stands on a small stage, wearing a typical cap to show his identity, and introduces some heated topics from a humorous perspective. Wang Nima is the gold medalist of Bao Zou Big News Event. In the program, his uniquely humorous views can spit out what other people cannot spit out. His meticulous attention to detail makes the program almost perfect. Compared to other well-known entertainment presenters whose characters are almost perfect, Wang Nima's character can be said to be counterproductive. In the show, Wang Nima is stingy, glass heart, temper and easy to be angry. His words sometimes are accurate and naive, but often are serious nonsense. However, this set of characters have attracted more people's attention, and make himself very approachable.

In addition, regarding to our fast pace of life, Bao Zou Big News Event simplifies the content of program, and the duration of each program is less than half an hour. They use the sharpest and humorous language to review recent news and satirize some social phenomena by micro films, some odd songs and dances with the purpose of bringing people enlightenment. We have to recognize that Bao Zou Big News Event gives contemporary people an opportunity to catch up with the latest hot events without spending too much time.

Last year, owing to Wang Nima's response to a teenager that if he was not willing to be arranged by his parents all the aspects of his life, he should learn to resist and speak out his own opinions. Then unfortunately, this episode was soon banned to broadcast on the Internet, and Bao Zou Big News Event facedan unprecedented dilemma as the result of instigating teenagers. After this incident, the talk show had to change another host, and some fans said that Bao Zou Big News Event was a bit of different from what it used to be.

\subsection{A Date with Luyu}

The China TV talk show A Date with Luyubroadcasts on the Phoenix Television and Central Channel weekly. It consists of a regular anchor host-Chen Luyu, and a celebrity guest who could be an actor, sportsman, singer, or writer. This China TV talk show aims at giving the celebrities a platform to discuss their personal struggles in achieving success. It is a standard chat show which treats guests and studio participants with some degree of deference. The audience of this Talk show ranges from young to old. As for Luyu, the interviewee is the center of the show while the interviewer is mostly 
leading the interview with questions, rephrasing the questions, listening attentively and giving feedback to the answers.(Lee \& Chen \& Tan, 2013)

A Date with Luyu is probably the most popular Chinese interview Talk show. The program seeks out people with special experiences, then witnesses history, thinks about life, discovers directly secrets of the soul from the experience of life and creates a novel conversation record. Both the host Luyu's concern about people and the interviewee's mind dialogue are the touching points of this talk show. $\mathrm{Lu} \mathrm{Yu}$ believes that everyone's story is wonderful. She once said that she was more interested in people and stories and she has no interest in the truth.

On March 5th, 2007, an article titled "Chen Luyu: China's 'Oprah' appeared on the CNN website. The article awarded the reputation of "Chinese Oprah" to Chen Luyu, the famous host of Phoenix Satellite Television, and gave full attention and affirmation to her talk show---A Date with Luyu with Chinese characteristics which she had persisted in for five years. But even so, Luyu does not dare to claim her success, but simply calls herself "a host of small achievements", because she thinks that achievements and successes are too significant.

\section{The Hosting Style In American TAlK SHOW}

\subsection{Oprah Winfrey Show}

Oprah Winfrey Show is the most famous television talk show in America. Oprah's program is a "rapport-talk" --a conversation only between the host and the guest, which is the basis of a friendship between women. And exactly she knows how to run the friendship between women. She understands women's feeling and know how to comfort and support them. "Watching her show, just like listening to a good friend to talk. Oprah can honestly share her unfortunate experience with others."(Chen, 2014:99)

Oprah is a well-known "talk show queen" in the United States. She is an actress, publisher, philanthropist, and more. She was originally from a poor area in the south of the United States in the early years and was a black and illegitimate child. She went to a juvenile prison and gave birth to a child at the age of 14, she smoked, took drugs and drank alcohol. But the "problem girl" nowadays relies on her extraordinary charisma, stands out in the U.S. interviews with television programs and wins hearts and minds from millions of television viewers in the United States .

She is the first black female newscast in the history of the United States, her name has become "black power" representative. She enjoys the nation's highest talk show ratings, and fans in 132 countries around the world. The book recommended by her show has always been bestseller. She was one of the "100 Most Influential Celebrities in the 20th Century" by Time magazine and the first black woman to board the Forbes Rich List. Vanity Fair commented that Oprah's influence in popular culture may be greater than any university professor, politician, or religious leader except the Pope.

\subsection{Late Show with David Letterman}

Late Show with David Letterman is a famous American late-night entertainer talk show hosted by David Letterman on CBS. It won the Emmy Award for best variety show. As host of both Late Night and Late Show for more than 30 years, Letterman also won the title of the best talk moderator and surpassed Johnny Carson as the longest running late-night talk show host in 2013.Late Show with David Letterman, which started in 1993, ranked seventh on the TV Guide's 50 Greatest TV Shows of All Time. In the same year, it also ranked at 41th on TV Guide's 60 Best Series of All Time.

The show's opening credits featured a series of shots of New York City as the CBS Orchestra performed the Late Show theme (a livelier variation of the jazzy LateNight theme). The announcer presented the names of that night's guests, as well as Paul Shaffer and the CBS Orchestra, then introduced Letterman. On rare episodes, the show began with a cold opening as Letterman, dressed casually, briefly interacted with a celebrity or performed a short sketch backstage before the traditional opening sequence began.

David Letterman's signboard is his smile which shows his teeth. He often pleases the audience by taking himself as a joke. In order to make the program attractive, Letterman tells jokes by using news 
from celebrities from time to time, or makes riddles to test program guests.

\subsection{The Tonight Show Starring Jimmy Fallon}

In China, there is a talk show named Tonight's Post-80s Talk Show I mentioned above, which adopts The Tonight Show's idea and makes some innovations to make it characteristic Chinese talk show.

The Tonight Show is a night talk and variety show created by NBC in 1954. Each episode consists of monologues, interview guests, and bands. It lasts for about 50 minutes. By 2014, 20 shows have been broadcasted. More than 2,000 episodes in the quarter have become well-known in the United States. In May 1992, Jay Leno, the famous comedian, became the fourth host of the show. Leno is so humorous and always takes care of guests' feelings to avoid their embarrassment, from which he earned numerous audiences and made this show a leader of talk show. On February 17, 2014, Jimmy Fallon took over NBC's veteran talk show The Tonight Show from Jay Leno and renamed The Tonight Show Starring Jimmy Fallon.

Jimmy Fallon hosts the Tonight Show and interviews celebrities, plays games with them and has a musical or comedic guest perform. He once said that his show would stick to the talk show format perfected by Johnny Carson four decades ago-- monologue, desk comedy bit, two guests and a band.

In 2014, The Tonight Show Starring Jimmy Fallon won the Primetime Emmy Award for Outstanding Creative Achievement in Interactive Media - Enhancement to A Television Program or Series and the Critics' Choice Television Award for Best Talk Show.

\section{Differences Of Hosting Styles Between China And American Talk Shows}

\subsection{Selection of Hosts}

Due to differences in history, culture and other factors, the development of the China-US talk show each formed its own style and characteristics. When choosing the hosts, America attaches great importance to experience, while China pays attention to educational background. When choosing a host, the most important thing for the American television industry is not personal appearance and instrument, but knowledge and experience. Such as Peter Jennings, though only secondary education, is knowledgeable, profound thinking, and is considered to have a scholarly temperament and philosopher mind. In comparison, talk show host in China is inferior in age and social experience. The reason is very simple---China's earliest television talk show is launched in 1993 by the Oriental Television named "Oriental Broadcasting Room." Short-term development does not allow our country to produce professional hosts adapting to talk show.

In other words, you may find that in Chinese interview, when employers ask job seekers that where they graduate from, they are more willing to hear that you graduated from key universities or you got the master's degree in key universities. But if you say you graduated from a general undergraduate university, I cannot assure the employers will say that it is okay and then give you this opportunity to improve your skills from this job. Nowadays more and more companies realize the importance of experience. And the different attitude towards experience and educational background, talk shows in America seem more connected to social events that most people concern about.

\subsection{Selection of Topics}

From the aspect of topic selection, America emphasizes freedom and China emphasizes leadership. The topics covered by the American talk show vary ranging from international politics, ethnic conflicts, to domestic violence, and the relationship between the two sexes, focusing on the novelty of the topic. Sometimes even celebrity politicians are "rumored." Politicians are most likely to appear on the celebrity talk shows, prototypical guests are typically cultural luminaries such as movie and television stars, musicians, and comedians. The style of the celebrity talk show is personal, congenial, and conversational. (Loeb, 2017)

In our country, the topics of the talk show focus more on education and publicity. At present, most of China's talk shows are not operated as entertainment shows. The topics are generally concentrated on social education or news topics. There is a clear direction of public opinion in the viewpoints. Due to a narrow range of topics, most of the topics are some less sensitive social issues. But many high- 
ranking Chinese officials have recently changed their low-key persona and discussed sensitive issues on television talk shows. It does not mean that the Chinese officials are personally open to the media. Unlike politicians in western democracies who are more used to media pursuit, such as one-on-one interviews, press conferences, and live debates on television, most Chinese officials try to avoid overpublicity and prefer to operate within a secretive decision-making apparatus. (Zhu \& Wang, 2013)

\subsection{Interaction between Hosts and Audiences}

From the perspective of hosts and audiences, America advocates harmony in the field and Chinese emphasize the performances of guests. For the American television audience, speaking to television is more of a show, they are indulged in this magical effect of being famous all over the world. Talk show is hosted in a relaxed and happy way, which makes the host closer to audiences, then achieves a degree of harmony. On the contrary, in China, the audiences at the show site are more elegant, and passive as spectators to watch the shows on the stage. Conversations between host and guests constitute the vast majority of programs. As for audiences, both the host or guests on the stage are "distant" stars.

It's obvious to notice the differences from talk shows between America and China. For instance, when watching Bao Zou Big News Event, we find there is only one host standing on the center of stage and talking about satirical news without audiences,so it is unnecessary to analyze the interaction between hosts and audiences. Also, in A Date with Luyu, the roles audiences play in this show are just like story listeners, and they come to scene then sit silently, and finally they may be moved or encouraged without saying a word or expressing their own opinions. However, in the American talk shows, audiences participate actively and there is no need to hide the dispute between guests and audiences. Liberty and heated discussion are highly advocated.

\subsection{Degrees of Economic Development}

Economy is "that complex of activities which is concerned with the production, distribution, exchange, and consumption of scarce goods and services".(Bandelj\& Morgan, 2015) Culture can be defined as "symbolic vehicles of meaning, including beliefs, ritual practices, art forms, and ceremonies, as well as informal cultural practices such as language, gossip, stories, and rituals of daily life".(Bandelj\& Morgan, 2015) The economy is embedded within the 'ideas, public narratives, and explanatory systems' that serve to create the necessary conditions for certain ways of organizing the economy to be normalized.(Bandelj\& Morgan, 2015) In general, in a country, the more developed the economy is, the more advanced the culture will be.

Specifically speaking, the U.S. talk show is a purely commercial mode of operation, so nothing for the talk show host is unmentionable as long as it is profitable for the show. In developing country China, though many programs are also pursuing high ratings to obtain economic benefits, in general, our social system requires the mass media to focus on social interests, to advocate social responsibility and collectivism. Our society requires the coordination of individualism and collectivism, and if necessary, individualism should submit to collectivism.

\subsection{Differences of Cultural and Political Background}

\subsubsection{Differences of Political Background}

When talking about cultural background, we have to refer to the different political backgrounds of these two countries. In China, hosts must be loyal to the Communist Party and Chinese people, to our country's laws, to our ethos, and to the cultural mission and social responsibility. On the contrary, American hosts can make decision by their own value and position, for the government plays a role of supporter behind them.

\subsubsection{Differences of Cultural Background}

The differences of political background, to a large extent, are responsible for the differences of cultural background. American society pursues liberty, advocates adventurism, and believes in individualism. So there aren't any restrictions on their topic choices, including the sensitive topics, such as cultural differences and racial differences. While the traditional culture of China advocates that collective interests prevail over individual interests, as a result, Chinese hosts have no choice but 
to select some social issues which are not so sensitive and can make contributions to social education.

\subsubsection{Differences of Social Atmosphere}

In addition, talk shows are part of daily life in America. From early in the morning as people get ready for work until late at night as they slide into sleep, celebrity talk shows play on television. "These shows are not just a steady background hum to American life, but are influential on public discourse."(Loeb, 2015) Nevertheless, in China, fewer and fewer people spend time on reading because of the high-speed life style. So it is comprehensible that watching talk shows is regarded as a way of pastime, and Chinese people do not attach too much importance on talk shows.

\section{CONCLUSION}

Although there are differences on the selection of hosts, selection of topics, interaction between hosts and audiences, degrees of economic development and differences of cultural background between Chinese and American talk shows, the standards on truth, goodness and beauty are the same. This also shows that the program requirements of the host is consistent in the West and the East. In the era of intensified competition for television programs, we should actively learn from the experience of outstanding U.S. talk show hosts, learn from their charming personality, learn from their strengths and combine with the media environment in our country so as to explore a successful path for the development of our television talk shows.

Tonight's Post-80s Talk Show draws on some European and American shows, the reason for its success lies in an overall grasp of the show by the creative team. Clear audience position, distinctive host style, and the localization of the program make the show a new look. This enlightens us that we should dare to innovate, we must dare to reform, and only by constant innovation and continuous progress can we succeed. (Yang, 2017:199)

Though it cannot be denied that the talk shows in China are not designed so beautiful and the phenomenon that many talk shows copy foreign shows directly still exists. It takes a long time for Chinese talk shows to explore a destination which is exactly suitable for them. And the host must hold great responsibility for it. A good talk show host should always stand in the forefront of the times, maintain its advanced nature and creativity, but also maintain a unique perspective. A good talk show host should present a talk show with Chinese characteristics in lively language for the audience, and thus promote the localization development of talk show in China.

\section{REFERENCES}

[1] Bandelj, N \& Morgan, P.J. (2015). Culture and Economy. University of California.

[2] Chen, H. R. (2017). How to Strengthen Creative Thinking of Talk Show Host in the New Media Era. The House of Drama, 17,124-124.

[3] Chen, Y. (2014). A Comparative Study of the Characteristics of the Hosts of the Sino-American Talk Show. Audio-visual Aspect, 3, 99-100.

[4] Guo,M. R. (2016). Study on Entertainment Talk Show in China. Heilongjiang University.

[5] Ilie, C. (1999). Question-response Argumentation in Talk Shows. Journal of Pragmatics, 31,975-999.

[6] Lee, C. L. \& Chen, Y. \& Tan, G. L.(2013). Silence and Face-work in Two Chinese Talk Shows. Discourse, Context \& Media, 2, 52-74.

[7] Loeb, L. (2015). The Celebrity Talk Show: Norms and Practices. Discourse, Context \& Media, 10, 27-35.

[8] Loeb, L. (2017). Politicians on Celebrity Talk Shows. Discourse, Context \& Media, 20,146-156.

[9] Yang, X. R. (2017). A Brief Analysis on the Success of Tonight's Post-80s Talk Show. Popular Literature and Arts, 16,199-199.

[10] Zhu, J. \& Wang, X.(2013). Unveiling the Political Elite: High-Ranking Chinese Officials on Television Talk Shows. Journal of Chinese Political Science, 18,117-137.

[11] Zhou, X. \& Wu, Y. (2008). Authenticity through Cooperation of the Host and the Guests in a Chinese TV Talk Show. Cross-cultural Communication, 4, 81-89. 


\section{AUTHORS' BIOGRAPHY}

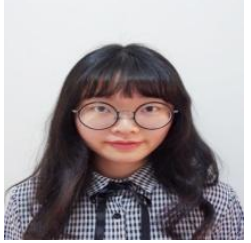

HONGLI WU was born in Lishui, China in 1997. She is currently a college student in Zhejiang Ocean University, Zhoushan, China. Her research interests include cross-culture communication and English translation.

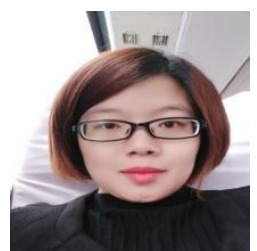

JINGJING LU is an associate professor in Foreign Language College, Zhejiang Ocean University, Zhoushan, China. She received her M.A. degree in linguistics and applied linguistics from Huazhong University of Science and Technology, China in 2006. Her research interests include cross-culture communication, English teaching and discourse analysis.

Citation: Hongli Wu, Jingjing Lu. "Comparative Study on Talk Shows in China and America from Hosting Styles." International Journal of Humanities Social Sciences and Education (IJHSSE), vol 5, no. 5, 2018, pp. 42-48. doi: http://dx.doi.org/10.20431 /2349-0381.0505006.

Copyright: (C) 2018 Authors. This is an open-access article distributed under the terms of the Creative Commons Attribution License, which permits unrestricted use, distribution, and reproduction in any medium, provided the original author and source are credited. 